\title{
The impact of electrical power quality indicators on the accuracy of industrial power supply system management
}

\author{
Alexander Sevostyanov ${ }^{1, *}$, and Gennady Vagin $^{1}$ \\ ${ }^{1}$ Nizhny Novgorod State Technical University n.a. R.E. Alekseev, Minin str., 24, Nizhny Novgorod, Russia
}

\begin{abstract}
The impact of power quality indicators and synchronized vector measurement device errors on electrical mode parameter assessment is examined with using a model of a simple industrial power supply system. There are underestimated requirements for the accuracy of synchronized vector measuring devices (SVMDs) with regard to their use in technical solutions designed to control the power supply modes at industrial enterprises.
\end{abstract}

\section{Introduction}

As shown in [1], electricity quality (EQ) is the most important factor affecting the efficiency of power supply systems in industrial enterprises.

The issue of increasing EQ is the most acute in industrial networks, to which a large number of receivers are connected, with asymmetrical, sharply variable and non-sinusoidal operation.

Voltage deviations, oscillations, non-sinusoidality and asymmetry in the networks are random values and can lead to consequences such as:

- the correct functioning of safety equipment and automation;

- measurement errors of values characterizing the operating parameters of the industrial power grid;

- disruption of technological processes.

Connection to the power grid of receivers with nonlinear voltamper characteristics affecting EQ leads to interference not only in the industrial plant's power grid, but also in the generator buses. In order to manage the mode of the industrial power network, it is necessary to have reliable information about the voltage values at different points in the company's network, the current values in the lines and the amount of power transmitted via feeders. SVMDs are at present widely used to accomplish this task.

\section{Values of electromagnetic interference introduced into the network by industrial electrical receivers}

Let us consider the levels of electromagnetic interference (EMI) introduced into the network by the most common industrial electrical receivers.

Electrical Arc furnaces (EAFs). Among electrotechnological installations, EAFs generate the highest levels of interference [2], of which the main ones are: deviations, dips and voltage fluctuations, non-sinusoidal and unbalanced voltage. At the same time, the greatest interference values are observed when the furnace is operating in the metal melting mode, Table 1 [2].

Table 1. EMI limits in the buses feeding EAFs

\begin{tabular}{|c|c|c|c|c|}
\hline EAFs voltage, $\mathrm{kV}$ & Voltage deviations, $\%$ & $\begin{array}{c}\text { Voltage } \\
\text { fluctuations, } \%\end{array}$ & $\begin{array}{c}\text { The total voltage } \\
\text { harmonics, } \%\end{array}$ & $\mathrm{C}_{2 \mathrm{U}}, \%$ \\
\hline $6-10$ & from -6 to +6 & $1-7$ & $0.5-5$ & $1-6$ \\
\hline 35 & from -5 to +5 & $1-6$ & $0.7-4$ & $0.5-5$ \\
\hline 110 & from -6 to +7 & $0.5-3$ & $0.1-2$ & $0.5-3$ \\
\hline
\end{tabular}

Electro-slag refining furnaces. These furnaces have a quiet operation mode with a gradual reduction in current consumption by the end of the melting process [3]. Single and two-phase furnaces create voltage asymmetries of up to $4 \%$ in the grid.

Welding machines in their operation create voltage gaps in the grid of which the magnitude depends on the capacity of the welding machine and the power source [3]. For example, embossed and spot welding machines create voltage dips up to $7 \%$ deep. Voltage dips of up to $19 \%$ are created by butt and spot welding machines in their work. At the same time the duration of voltage dips for spot, embossed, multi-point and spot welding

\footnotetext{
* Corresponding author: sevosaa@gmail.com
} 
machines ranges from 0.02 to 1.0 sec. and for butt welding machines from 0.2 to 20 sec.

The value of the asymmetry coefficient in welding networks ranges on average from 1 to $5 \%$. It should be noted that these asymmetry coefficient values are shortlived with large pauses between them [3].

Table 2 shows the harmonic content in current and voltage generated by the various electric welding machines at the generator buses [3].

Table 2. Harmonic component values

\begin{tabular}{|c|c|c|c|c|}
\hline \multirow{2}{*}{ Harmonics numbers } & $\begin{array}{c}\text { Amplitude range for current harmonics (\%) of } \\
\text { the total current amplitude }\end{array}$ & $\begin{array}{c}\text { Amplitude range for voltage harmonics (\%) of } \\
\text { the total voltage amplitude }\end{array}$ \\
\cline { 2 - 5 } & $\begin{array}{c}\text { Single point welding } \\
\text { machines }\end{array}$ & $\begin{array}{c}\text { Multi-point welding } \\
\text { machines }\end{array}$ & $\begin{array}{c}\text { Single point welding } \\
\text { machines }\end{array}$ & $\begin{array}{c}\text { Multi-point welding } \\
\text { machines }\end{array}$ \\
\hline 2 & $0.3-5.0$ & $0.1-4$ & $0.05-1,0$ & $0.08-0.8$ \\
\hline 3 & $12-30$ & $4-26$ & $1-3.5$ & $1-2.5$ \\
\hline 4 & $0.2-3.0$ & $0.08-3$ & $0.02-0.7$ & $0.01-0.8$ \\
\hline 5 & $4-15$ & $3-10$ & $0.7-2$ & $0.4-2.3$ \\
\hline 6 & $0.2-0.25$ & $0.07-2,2$ & $0.02-0,4$ & $0.03-0.75$ \\
\hline 7 & $2-8$ & $1,3-5$ & $0.4-2$ & $0.2-1.6$ \\
\hline 8 & $0.2-2$ & $0.07-1,5$ & $0.02-0.3$ & $0.07-1.5$ \\
\hline 9 & $1-5$ & $1.1-5$ & $0.02-1.5$ & $0.4-1.1$ \\
\hline 10 & $0.1-1.5$ & $0.07-1,3$ & $0.03-0.3$ & $0.04-0.5$ \\
\hline
\end{tabular}

Rolling mills. Synchronous, asynchronous and DC motors are used as electric drives in rolling mills. Rolling mills with synchronous and asynchronous electric drives are sources of voltage fluctuations and dips. Mills with current converters generate interference in the form of fluctuations, dips and non-sinusoidal voltage. Table 3 shows the limits of variation in the interference value generated by different types of mills [4].

Table 3. Electromagnetic disturbances caused by rolling mills with $6,10 \mathrm{kV}$

\begin{tabular}{|l|c|c|c|}
\hline \multicolumn{1}{|c|}{ Types of mills } & $\begin{array}{c}\text { Voltage } \\
\text { deviations, } \%\end{array}$ & $\begin{array}{c}\text { Voltage } \\
\text { fluctuations, } \%\end{array}$ & $\begin{array}{c}\text { The total coefficient of voltage } \\
\text { harmonics, } \%\end{array}$ \\
\hline Hot-rolled sheets & from -10 to +5 & $1-2$ & $4-14$ \\
\hline Blooming, slabbing, reversing cold mills & from -10 to +5 & $5-20$ & $10-30$ \\
\hline Unreversing cold mills & from -10 to +5 & $10-30$ & - \\
\hline
\end{tabular}

Presses at work create voltage dips. The maximum range of voltage dips during press operation is $1-1.8 \%$ with a frequency of up to $0.2 \mathrm{~Hz}$. Automatic press lines create voltage dips up to $5 \%$ deep with a frequency of up to $0.17 \mathrm{~Hz}$.

Conveyors, fans and compressors are sources of voltage dips at the moment the equipment starts up. The depth of voltage dips do not exceed: $1.2 \%$ for conveyors, $3-5 \%$ for fans, and $4-6 \%$ for compressors.

\section{Influence of electric energy quality parameters on digital processing of current and voltage}

The peculiarities of processing current and voltage signals under conditions of their sinusoidal distortions are well studied in scientific and technical literature [5]. A number of authors have proposed algorithms $[5,6,7$, 8] that reduce the negative impact of EQ disturbances on the incorrect operation of digital measuring devices in industrial power supply systems.

In order to build an electricity supply system that takes into account electromagnetic compatibility, it is necessary to know the nature and the level of interference generated by the electrical receivers that are part of the system. The presence of a large number of electronic and digital elements in smart industrial power supply systems that are sensitive to conductive interferences requires a detailed study of the effects of these electromagnetic interferences. If the power supply system is designed without taking into account the effect of EQ indicators, or a new source of distortion in the form of an emergent non-linear load, the system may end up in unplanned, dangerous and even emergency modes.

The development of existing power supply systems is impossible without modern monitoring systems based on digital measurements and processing of current and voltage signals. An important role in such systems will be assigned to SVMDs, as well as protection and control devices, including SVMDs. The most important problems associated with the organization of synchronized measurements in industrial power supply systems are related to their topology: shorter feeder lengths; buses located at short distances from each other and causing small angular differences in the measurement of current and voltage complexes; higher harmonic content; wider ranges of negative impact of 
frequency deviations caused by emergency events in industrial power supply areas.

\section{Requirements for digital processing of current and voltage signals in intelligent industrial power supply systems}

Many protection and control devices with integrated SVMDs capabilities may have errors in the evaluation of currents and voltages in transient modes, especially under conditions of deviations in industrial frequency [5, 6].

The deviation of current and voltage signal parameters has a number of limitations [9], which are normalised for SVMDs in standards [10] by setting permissible errors. According to [10], the main accuracy indicators of synchronised vector measurements are: Total Vector Error (TVE - Total Vector Error), Frequency Error (FE - Frequency Error) and Speed Error.

TVE determines the error between the theoretical value of the complex current or voltage vector and its measured value as a percentage. However, it must be stated that TVE is a reliable tool only in stationary modes and does not meet the requirements for accuracy of measurements in transient modes, especially considering the requirements of TVE in industrial power supply systems. Thus, calculating TVE can serve as a comprehensive indicator for calculation accuracy in regards of current and voltage parameters, It can also be used to assess the modes of intelligent power supply systems.

TVE includes three sources of interdependent errors: amplitude, phase angle and synchronization error in the time of instantaneous discrete values. The total allowable change range for TVE must be within $1 \%$. If only one of the above error sources is selected, 1\% TVE can be obtained with amplitude error $\pm 1 \%$; phase angle error $\pm 0.573^{\circ}$ or synchronisation time error $\pm 31 \mu \mathrm{s}$ for $50 \mathrm{~Hz}$ [10].

\section{Influence of SPMD errors on power transmission parameters}

Let's look at the simplest diagram (Figure 1) explaining the relationship between the supply voltage $U_{l}$ and the consumer load $U_{2}$. Figure 1 shows examples of radial $(a)$ and main (b) power supply schemes for industrial consumers. In the case of Figure $1 a$ points 1 and 2 (the SVMD installation sites) are located in $10 \mathrm{kV}$ buses of the main step-down substation and $10 \mathrm{kV}$ buses of the shop step-down substation. In the case of Figure $1 b$, points 1 and 2 are located in $10 \mathrm{kV}$ buses in the TS1 and TS2 shop substations.

In Figure $1 P_{l}$ and $Q_{1}$ the active and reactive power measured in the generator buses; $P_{2}$ and $Q_{2}$ represent the active and reactive power flows in the load buses; $Z$ is the complex impedance of the electric-power transmission line; $\dot{U}_{1}$ и $\dot{I}_{1}$ - the complex voltage and positive-sequence current in the generator buses; $\dot{U}_{2}$ и $\dot{I}_{2}$ - the complex voltage and positive-sequence current in the load buses; 1 and 2 - the locations of installation of SVMDs.

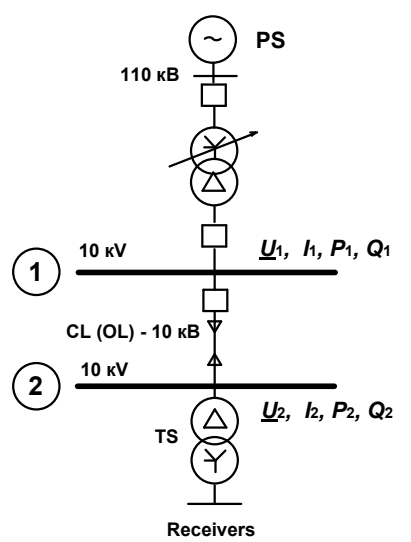

(a)

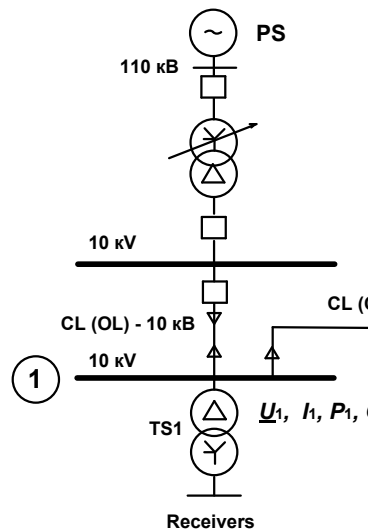

(b)
$\mathrm{L}(\mathrm{OL})$ - $10 \mathrm{kV}$

Cш $10 \mathrm{~KB}$

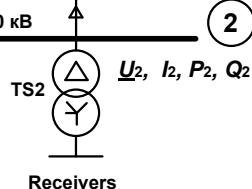

(2)

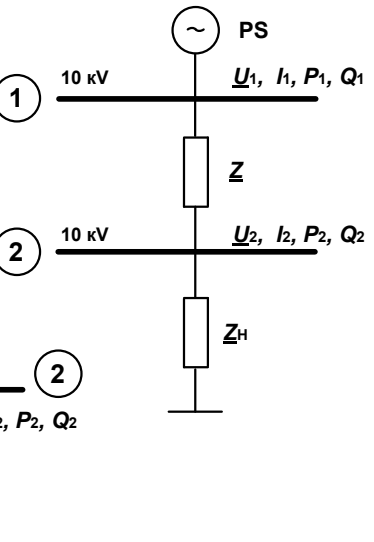

(c)

Fig. 1. An example for assessing the accuracy of power transmission measurements for radial (a) and main (b) power supply schemes, (c) replacement scheme (TS - transformer substation; PS - power system).

Let us assess the impact of TVE related to voltage measurements on the power flow. The following correlation is characteristic of the model (Figure 1)

$$
\dot{U}_{1}=\dot{U}_{2}+\underline{Z} \cdot \dot{I}_{2}
$$

therefore, the equation for the current in the load buses is as follows:

$$
\dot{I}_{2}=\left(\dot{U}_{1}-\dot{U}_{2}\right) / \underline{Z}
$$

When presenting the current $\dot{I}_{2}$ in polar coordinates, we receive

$$
\begin{gathered}
\dot{I}_{2}=\left(\left|\dot{U}_{1}\right| \cdot e^{j \varphi 1}-\left|\dot{U}_{2}\right| \cdot e^{j \varphi 2}\right)|| \underline{Z} \mid \cdot e^{j \alpha}, \\
\dot{I}_{2}=\left(\left|\dot{U}_{1}\right||| \underline{Z} \mid\right) \cdot e^{j(\varphi 1-\alpha)}-\left(\left|\dot{U}_{2}\right||| \underline{Z} \mid\right) \cdot e^{j(\varphi 2-\alpha)} .
\end{gathered}
$$

The total power transmitted in the load buses is as follows: 


$$
\begin{gathered}
S_{2}=P_{2}+j Q_{2}=\dot{U}_{2} \cdot \dot{I}_{2}{ }^{*}, \\
S_{2}=\left(\left|\dot{U}_{1}\right|\left|\dot{U}_{2}\right||\underline{Z}|\right) e^{j(\alpha-\varphi I+\varphi 2)}-\left(\left|\dot{U}_{2}\right|^{2}|\underline{Z}|\right) \cdot e^{j \alpha} .
\end{gathered}
$$

Introducing the variable characterizing the difference in voltage angles $\beta=\varphi 1-\varphi 2$, we come to the expressions of active and reactive powers in the form of

$$
P_{2}=\left(\left|\dot{U}_{1}\right|\left|\dot{U}_{2}\right||\underline{Z}|\right) \cdot \cos (\alpha-\beta)-\left(\left|\dot{U}_{2}\right|^{2}|\underline{Z}|\right) \cdot \cos \alpha,
$$

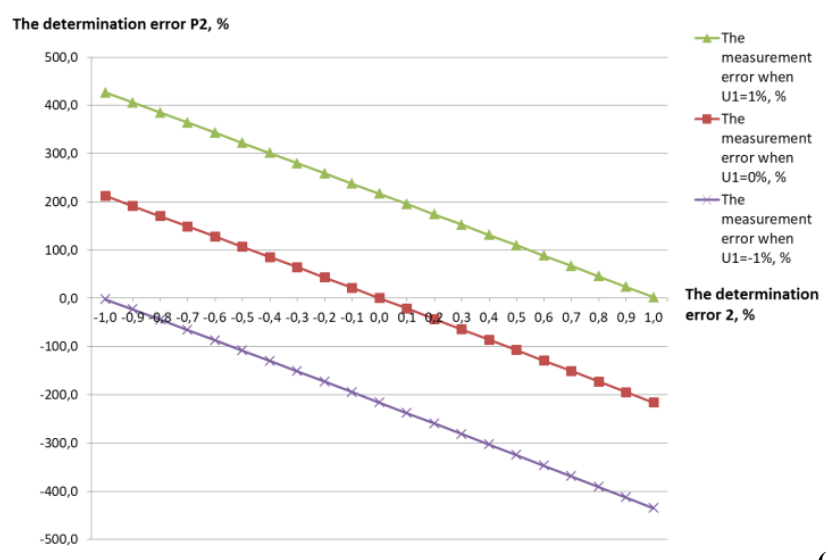

(a)
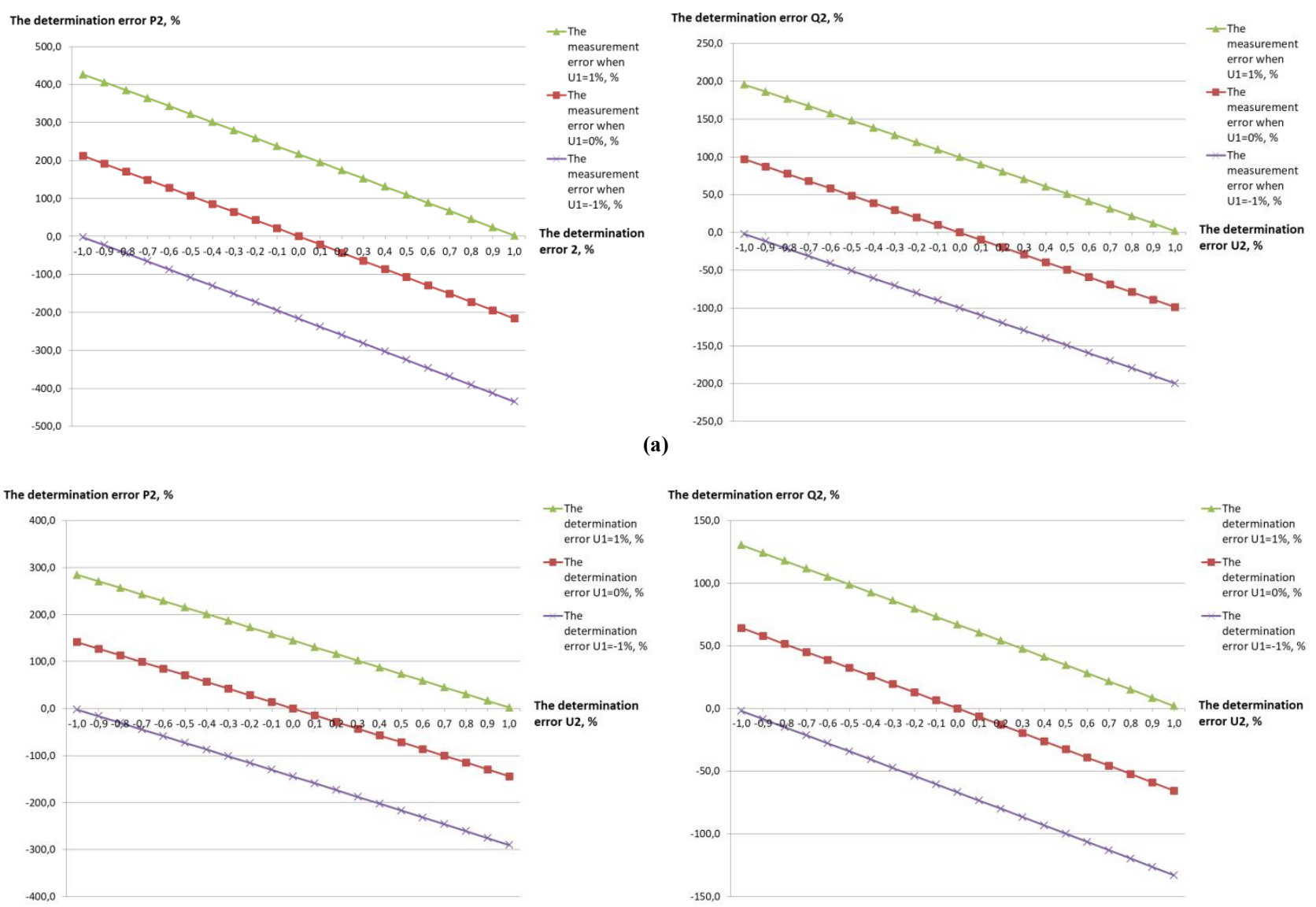

(b)

Fig. 2. Error calculation results in determining the active and reactive power transmitted to the receiver by CLs in the event of an error in the estimation of the voltage amplitude under the conditions of voltage distortion: $a$ ) with CLs of $1.0 \mathrm{~km}$. length; $b$ ) with CLs of $1.5 \mathrm{~km}$. length.

\section{An example of calculating estimation errors for active and reactive power parameters}

In order to analyze the adequacy of measurements, let us assume that the measurements are carried out under normal conditions, which are not extreme, in terms of generating a maximum level of interference (e.g. Tables 1-3). Under conditions of absolute measurement accuracy conducted by SVMDs, we believe that the TVE in a voltage amplitude measurement is $1 \%$ and is caused by electromagnetic interference.

For the analysis by expressions (2) and (3) we will consider the option of feeding receivers with a cable line (CL) of $10 \mathrm{kV}$ and a cross section of $70 \mathrm{~mm}^{2}$. We will

$$
Q_{2}=\left(\left|\dot{U}_{1}\right|\left|\dot{U}_{2}\right| /|\underline{Z}|\right) \cdot \sin (\alpha-\beta)-\left(\left|\dot{U}_{2}\right|^{2}|\underline{Z}|\right) \cdot \sin \alpha .
$$

Assuming that the resistance $\underline{Z}$ is constant and fully consistent with the transmission line parameters, and that the amplitude and phase values of voltage can vary within an error of $1 \%$ TVE, the equations (2), (3) can be used to estimate the accuracy of active and reactive power measurements. 
errors of other sources. Let us assess the potential errors of SVMDs that meet the requirements of $1 \%$ of TVE, but meet different conditions.

Let us assume that there is no phase angle error in voltage measurements, and the $1 \%$ TVE error is related only to the amplitude estimates generated by each SVMD. Thus, the amplitude of voltages can vary within the range of $0.9998 \pm(0.01 \cdot 0.9998)$ o.e. and $0.9950 \pm(0.01 \cdot 0.9950)$ o.e. in the generator buses and the load ones respectively.

The results of the error calculations performed to determine the active power and the reactive power delivered to the recivers via CLs $1.0 \mathrm{~km}$ long are shown in Figure $2 a$. For CLs of $1.5 \mathrm{~km}$ length, the results are shown in Figure $2 b$.

Calculations using expressions (2) and (3) show that the maximum error in the calculation of the active power and the reactive power exceeds $100 \%$ and there is a trend towards an increase in the error calculation when the feed line is short. In addition, the values of negative active power and reactive power have been identified, which can be described as the changes in power flow direction, the presence of capacitive load, or voltage regulator based on a shunt capacitor. However, none of these conditions correspond to the current scheme-mode conditions.

For these options, the largest errors were found when the voltages in the generation buses and the load ones are $+1 \%$ and $-1 \%$ TVE respectively.

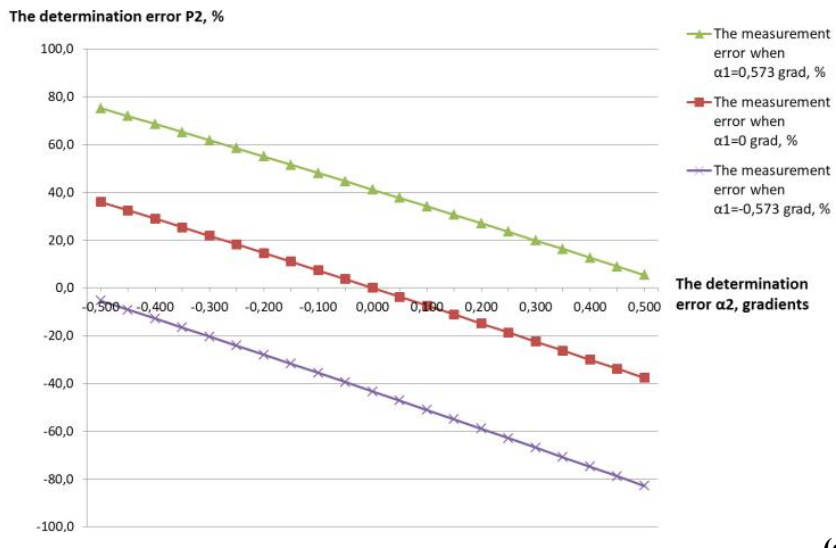

(a)
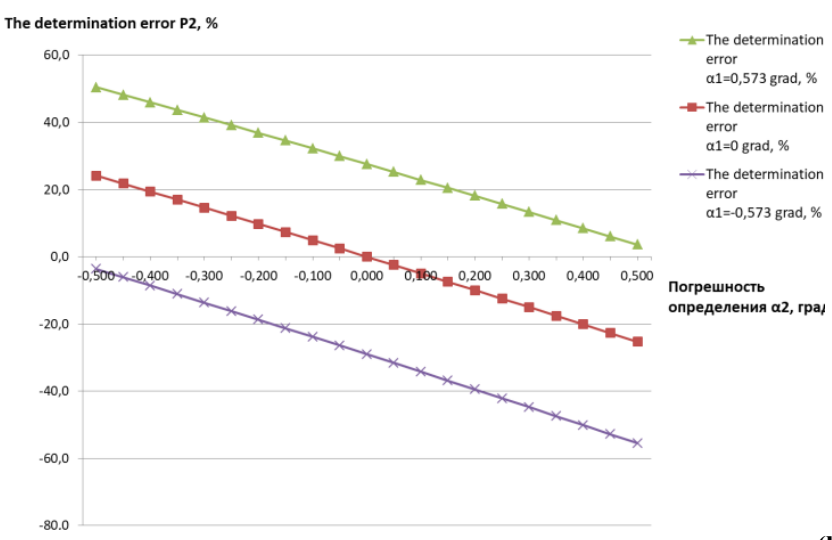

(b)

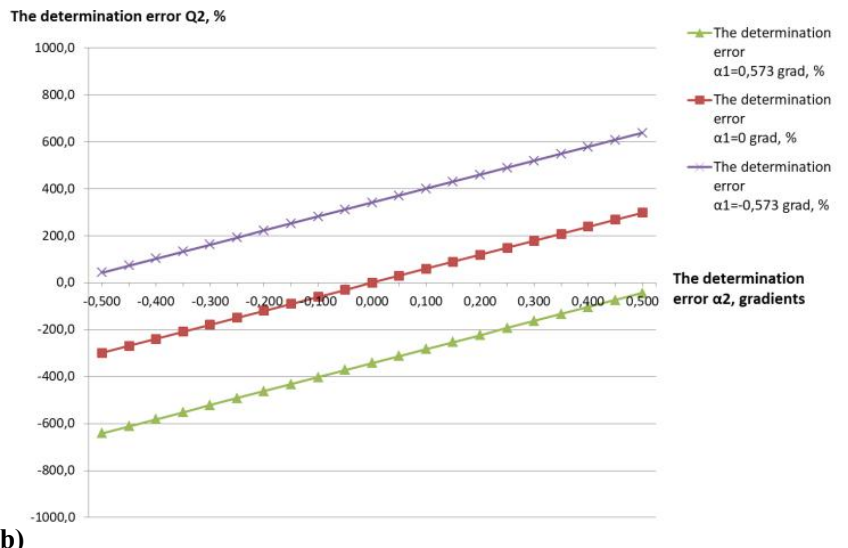

A similar amalysis was carried out by assuming a $1 \%$ TVE phase error. The condition was accepted that the amplitude estimates do not have errors. The phase angle deviations in the generator and load buses are within $\left(-0.0580^{\circ} \pm 0.5730^{\circ}\right)$ and $\left(00.0^{\circ} \pm 0.5730^{\circ}\right)$ respectively.

The results of the error calculations in determining the active power and the reactive power transmitted to receivers via CLs of $1.0 \mathrm{~km}$ and $1.5 \mathrm{~km}$ length are shown in Figure $3 a, b$ respectively.

The active and reactive power error calculations have demonstrated their essential value which has been more than $50 \%$ for the active power and more than $600 \%$ for the reactive power. Moreover, the highest values were found when the error of the phase angle in the SVMD voltage in the generator buses was close to $+1 \%$ TVE but on another SVMD was close to $-1 \%$.

Similarly, dependencies were formed when considering the option of feeding the load with a $10 \mathrm{kV}$ overhead power line (OL) $1.5 \mathrm{~km}$ and $1.0 \mathrm{~km}$ long. For the option of measuring the amplitude of the complex voltage, the maximum error in determining the active power and the reactive power was $\pm 97 \%$ and $\pm 61 \%$ for $1.5 \mathrm{~km}$ of overhead power lines $( \pm 145 \%$ and $\pm 92 \%$ for $1.0 \mathrm{~km}$ of overhead power lines). For the option of the phase angle deviation measurement error, the maximum error in determining the active power and the reactive power was $\pm 59 \%$ and $\pm 65 \%$ respectively for $1.5 \mathrm{~km}$ of overhead lines $( \pm 88 \%$ and $\pm 1025 \%$ for $1.0 \mathrm{~km}$ of overhead lines).

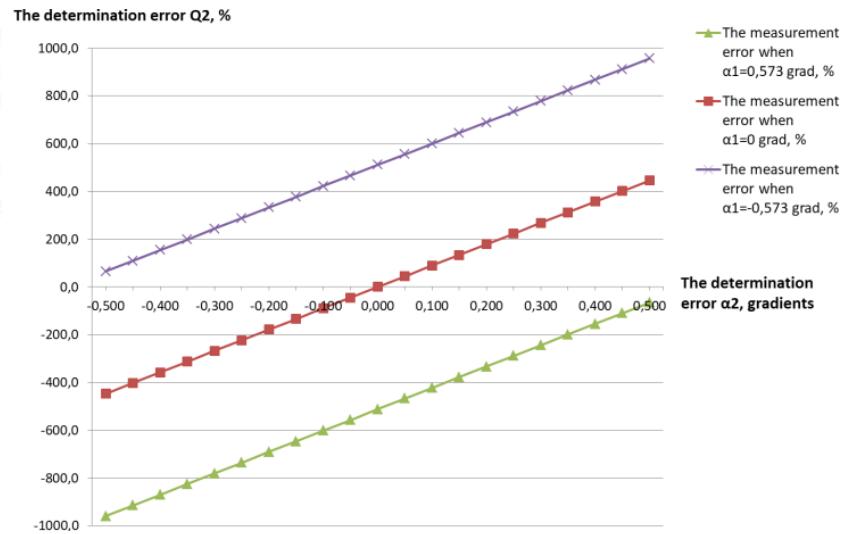
.

Fig. 3. Error calculation results in determining the active and reactive power transmitted to the customer via the CLs in the event of phase error in voltage distortion: $a$ ) with CLs of $1.0 \mathrm{~km}$ length; $b$ ) with CLs of $1.5 \mathrm{~km}$ length.. 
From the calculations presented, it becomes clear that the shorter the length of the feeders, the higher the power flow calculation error, and the 1\% TVE error does not meet the requirements of intelligent power supply systems.

It should be noted that taking into account the possibilities of managing modes in industrial power districts with distributed generation [11], the results of the simulation showed that it is necessary to increase the accuracy of SPMD to $0.1 \%$ of TVE.

\section{Conclusions}

The organization of regime management in modern intelligent industrial power supply systems requires the acquisition and collection of data at various points in the power network using synchronized vector measurements and digital processing of current and voltage signals.

The analysis of errors in measuring voltage parameters indicates that the requirements of existing standards for synchronized vector measurements do not meet the requirements of the existing standards for the assessment of the modes of operation of industrial power supply systems under conditions of electromagnetic interference.

\section{Literature}

1. L. Dobrusin, Energoekspert, 4, 30-35 (2008).

2. M. Smelianskiy, R. Mineyev, Arc electric furnaces influence on the power supply systems (in Russian) (Energia, Moscow, 1975).

3. A. Shidlovskiy, B. Borisov, G. Vagin, The electromagnetic compatibility of the industrial electrical receivers (in Russian) (Science Dumka, Kiev, 1992).

4. A. Loskutov, The increasing efficiency of electrical energy use at steel work power power supply systems: Authors' Disc. ... Doctor of Technical Sciences (MPEI Publishing House, Moscow, 1994).

5. P. Ribeiro, C. Dooké, P. da Silveira, A. Serkeira, Signal Processing in Intelligent Power Grids (TECHNOSPHERE, Moscow, 2020).

6. D. Belega, D. Macii, D. Petri, IEEE Trans. Instrum. Meas., 2, 388-401 (2014).

7. M. Kezunovic, S.Meliopoulos, V. Vittal, Application of Time-Synchronized Measurements in Power System Transmission Networks (Springer, NY, 2014).

8. D. Borkowski, F. Bien, IEEE Trans. on power delivery, 3, 1004-1013 (2009).

9. P. Ilyushin, A. Mokeev, V. Narovlianskiy, Methodical questions of the reliability research of the large energy systems Proceedings of the 90th session of the International scientific seminar named after Yu.N. Rudenko, 2, 28-37 (2018).

10. STO 59012820.29.020.011-2016. Relay protection and automation. Devices for synchronised vector measurements. Norms and requirements (JSC SO UES, Moscow, 2016).

11. P. Ilyushin, A. Kulikov, Automatic control with normal and emergency modes in energy districts with distributed energy (in Russian) (NIU RANKH \& GS., Nizhniy Novgorod, 2019). 